NASA Technical Memorandum 89876

AIAA-87-1948

\title{
Low Power dc Arcjet Operation With Hydrogen/Nitrogen/Ammonia Mixtures
}

Terry L. Hardy and Francis M. Curran

Lewis Research Center

Cleveland, Ohio

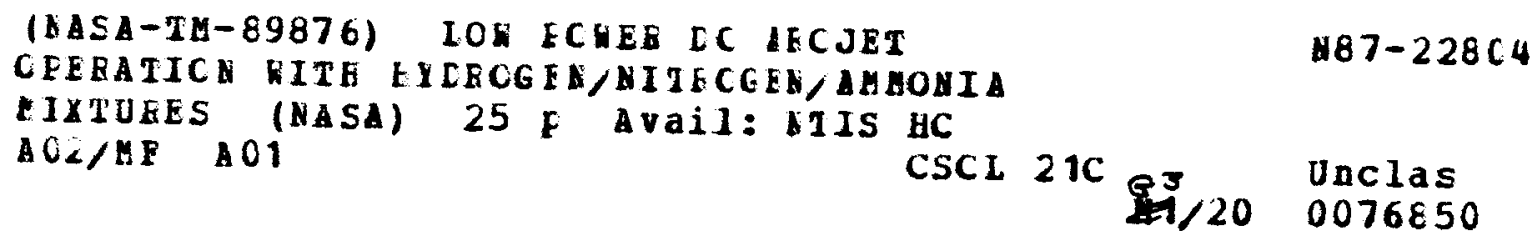

Prepared for the

23rd Joint Propulsion Conference

cosponsored by the AIAA, SAE, ASME, and ASEE

San Diego, California, June 29-July 2, 1987 


\title{
LOW POWER dC ARCJET OPERATION WITH
}

\section{HYDROGEN/NITROGEN/AMMONIA MIXTURES}

\author{
Terry L. Hardy and Francis M. Curran \\ National Aeronautics and Space Administration \\ Lewts Research Center \\ Cleveland, Ohio 44135
}

\section{SUMMARY}

An experimental investigation was conducted to determine the effect of gas composition and ambient pressure on arcjet operation. Arcjet operation in different facilities was also compared to determine the validity of tests in small facilities. Volt-ampere characteristics were determined for an arcjet using hydrogen/nitrogen mixtures (simulating both ammonia and hydrazine), hydrogen/nitrogen/ammonia mixtures, and pure ammonia as propellants at various flow rates. The arcjet had a typical performance of 450 sec specific impulse at $1 \mathrm{~kW}$ with hydrogen/nitrogen mixtures. It was determined that the amount of ammonia present in the gas stream had a significant effect on the arcjet voltampere characteristics. Also, hydrogen/nitrogen mixtures simulating ammonia gave arc characteristics approximately the same as those of pure ammonia. Finally, no differences in arc volt-ampere characteristics were seen between low $\left(10^{-4}\right.$ torr) and high ( 0.2 torr) ambient pressure operation in the same facility. A 3 to $5 \mathrm{~V}$ difference was seen when different facilities were compared, but this difference was probably due to differences in the voltage drops across the current connections, and not due to arcjet operational differences in the two facilities.

\section{INTRODUCTION}

Low power arcjet thrusters are currentiy being considered for use as auxiliary propulsion devices for geosynchronous communications satellites. A near-term application for the arcjet would be North-South station keeping of these satelitites. For this application the arcjet would provide significant propellant savings when compared to monopropellant hydrazine or resistojet thrusters due to its higher specific impulse (ref. 1). Hydrazine will probably be the near-term propellant of choice for compatibility with existing spacequalified propellant systems (refs. 2 and 3 ). In those systems hydrazine is stored as a liquid and is decomposed into hydrogen, nitrogen, and ammonia by a hydrazine catalyst bed gas generator. Although a recent study (ref. 4) has helped to quantify the gas composition exiting commercial gas generators, the exact amounts of hydrogen, nitrogen, and ammonia are not known, especially over the lifetime of the catalyst bed. Therefore, a study was conducted to determine the effect of gas composition as well as ambient pressure on arcjet operation. Also, the arcjet was tested in different facilities to determine the validity of experiments in small test facilities.

Low power arcjet operation on hydrogen/nitrogen mixtures has been reported previously (refs. 5 and 6 ). The experiments reported in each of these studies were performed with a ballasted power supply and an arcjet designed to provide weak vortex stabilization. In the first study, severe erosion was observed at 
the onset of testing and large mode changes were seen throughout the test. In the second study, mode changes were not observed but small voltage excursions and significant startup erosion were noted. In more recent tests a power supply designed to provide fast current regulation and a high voltage pulsed starting circuit (ref. 7) has been used in combination with an arcjet which incorporated strong vortex stabilization (ref. 8) to produce stable operation with nonerosive starting (refs. 9 and 10). For the tests described in this study a similar power supply/arcjet combination was used.

In addition to tests with hydrogen/nitrogen mixtures, tests with hydrazine (ref. 11) and ammonia (refs. 12 and 13) propellants have been performed at other laboratories. The hydrazine arcjet produced specific impulse values over $500 \mathrm{sec}$ at $1.4 \mathrm{~kW}$. The ammonia arcjet was a 1-kW class arcjet similar to the thruster described in reference 5. This thruster operated at $920 \mathrm{~W}$ input power and $550 \mathrm{sec}$ specific impulse. However, the thruster efficiency was quite low at 8 percent and severe erosion of the electrodes was observed. According to this study, this arcjet had an expected lifetime of less than $2 \mathrm{hr}$ with ammonia. However, vortex-stabilized arcjets were tested with hydrogen/nitrogen mixtures (ref. 14) and hydrogen (refs. 15 and 16) for over $100 \mathrm{hr}$ without serious detriment to the thrusters. Therefore, it was believed that the arcjet could operate with ammonia and an additional study with ammonia was deemed necessary.

In the present study thrust and voltage measurements were taken as a function of current for various flow rates of hydrogen/nitrogen gas mixtures simulating ammonia and hydrazine. Also, the volt-ampere (V-I) characteristics of an arcjet were determined using ammonia and hydrogen/nitrogen/ammonia gas mixtures. In addition, the effects of background pressure and facilities on the volt-ampere characteristics were examined.

\section{APPARATUS}

Tests were performed in two facilities. The first facility provided the low background pressures necessary for accurate thrust measurements of a hydrogen/nitrogen arcjet. This facility was a $1.5 \mathrm{~m}$ diameter by $5 \mathrm{~m}$ long chamber with four $0.82 \mathrm{~m}$ diameter 011 diffusion pumps and a rotary blower with a mechanical roughing pump (ref. 5). Each diffusion pump had a rated capacity of 15000 liters/min $(\sim 310 \mathrm{~g} / \mathrm{sec})$ at $10^{-4}$ torr $(0.0133 \mathrm{~Pa})$. The actual pumping performance was found to be typically $2.1 \times 10^{-4}$ torr $(0.0279 \mathrm{~Pa})$ at a flow rate of $0.034 \mathrm{~g} / \mathrm{sec}$ and $3.5 \times 10^{-4}$ torr $(0.0466 \mathrm{~Pa})$ at $0.043 \mathrm{~g} / \mathrm{sec}$. This facility could also be operated without diffusion pumps, using only the blower and roughing pump. In this case pumping performance was found to be 0.23 torr $(30.6 \mathrm{~Pa})$ at $0.048 \mathrm{~g} / \mathrm{sec}$. Testing was performed in a $0.92 \mathrm{~m}$ diameter by $0.92 \mathrm{~m}$ long port extension at one end of the facility. Use of this port allowed unobstructed access to the main facility during operation as well as port isolation for thruster changes through the use of a $0.92 \mathrm{~m}$ gate valve.

In this facility an eight channel strip chart recorder with a frequency response capability of $150 \mathrm{~Hz}$ was used to record arc voltage and current readings, thrust measurements, propellant flow rates, and propellant line pressure. A digital multimeter was also used to provide a redundant voltage measurement. The voltage reading was taken across the cathode and anode feed-throughs on the outside of the test port. The current was measured using a Hall-effect current probe. The output from this probe was sent to both a $50 \mathrm{MHz}$ oscilloscope and 
the recorder. An isolation amplifier was used in the voltage line between the test port and the recorder to prevent cross-channel noise problems. Thrust measurements were performed using a displacement-type thrust stand (ref. 9). Two digital flow meters incorporating thermal conductivity sensors were used to measure hydrogen and nitrogen gas flow in this factlity. Hydrogen and nitrogen propellants were mixed in the propellant inlet line before reaching the arcjet.

A pulse-width modulated power supply (ref. 7) was used to provide power to the arcjet in all tests. This power supply provided up to $130 \mathrm{~V}$ at up to $12 \mathrm{~A}$. Also, this power supply was equipped with a high voltage starting pulse generator, which provided a $4 \mathrm{kV}$ pulse once every second until arc current was sensed.

Because the diffusion pump facility was not equipped for ammonia operation an additional facility was required to operate the arcjet with ammonfa or hydrogen/nitrogen/ammonia mixtures. This facility, referred to as the bell jar facility, is shown in figure 1. The bell jar facility was a $0.46 \mathrm{~m}$ diameter, $0.64 \mathrm{~m}$ long chamber equipped with a single mechanical roughing pump. This pump had a rated capacity of 1700011 ters/min at 1 torr $(133 \mathrm{~Pa})$. In operation, an ambient pressure of approximately 0.5 torr (67 Pa) was maintained at a flow rate of $0.043 \mathrm{~g} / \mathrm{sec}$. A stainless steel cooling coil was placed in the bell jar exhaust line to prevent hot gases from exiting directly to the roughing pump.

The same chart recorder was used to record voltage, current, arcjet chamber pressure, and propellant flow rates at the bell jar facility. As in the larger facility, redundant measurements of voltage and current were obtained with an multimeter and a oscilloscope, respectively. Also, the arcjet propellant line pressure was obtained by a pressure transducer located in the propellant inlet line upstream of the arcjet. Thrust measurements were not taken in the bell jar facility. Flow measurements were obtained with commercially avaliable mass flow controllers. These controllers had a 0 to 1011 ter/min range and were operated individually by a multiple channel power supply. This supply was also equipped with a 0 to 5 Vdc output for each channel for input to the chart recorder. All gases were stored separately and mixed in the propellant feed line to the arcjet.

The arcjet used throughout the test was of the conventional, constrictedarc design. A cross-sectional schematic is shown in figure 2 . The anode housing was made of titaniated-zirconiated molybdenum (TZM) and the rear insulator of boron nitride. A stainless steel collar slid over the insulator and seated on a shoulder machined into the material. Two stainless steel plates and four bolts were used to hold these three pieces together. The anode/nozzle insert, called out in the figure, was made from two percent thorlated tungsten. The converging side of the insert was conical and had a half angle of $30^{\circ}$. The diverging, or downstream, side of the nozzle, also conical, had a $20^{\circ}$ half angle. The constrictor was $0.51 \mathrm{~mm}(0.020 \mathrm{in.})$ in length and $0.58 \mathrm{~m}$ $(0.023 \mathrm{in.})$ in diameter. The nozzle area ratio was approximately 165 . The exterior of the insert was ground to a $2.5^{\circ}$ taper as was the opening in the upstream face of the anode housing. When the insert was seated in the housing the tapered surfaces provided a gas-tight seal. 
To provide the vortex flow pattern used to stabilize arcjet operation, a stainless steel gas injection disk with graphite foll gaskets on either side was inserted into the housing to seat against the insert on one side. This insert is also called out in the figure. The two tangential injection holes in the disk were nominally $0.30 \mathrm{~mm}(0.012 \mathrm{in.})$ in diameter. Raised ridges were machined on both of the disk faces. These ridges compressed the graphite foll to provide a gas-tight seal when the entire unit was assembled. Immediately upstream of this disk was the front insulator. This was made of boron nitride and had both a centered hole for the cathode and grooves milled on its exterior surface to allow gas passage. A larger bore was used in the rear (upstream) of this insulator to accommodate an aluminum oxide tube, to be discussed below.

The cathode was made from 2 percent thoriated tungsten rod, $3.2 \mathrm{~mm}$ in diameter and approximately $190 \mathrm{~mm}$ in length. The tip was originally ground to a $30^{\circ}$ half angle and then polished to remove any rough edges. A stainless steel cathode holder was used to feed the cathode through the rear insulator. A commercial gas fitting on the end, exterior to the insulator, locked the cathode in place once the arc gap was set. The opposite end of the holder was tapped and a mating bolt, drilled out to allow the cathode to pass through it, was inserted into the rear insulator to secure the holder in place. The aforementioned ceramic tube extended nearly to this bolt. over the ceramic sleeve, from back to front in the design, were a boron nitride cylinder to cover the remainder of the face of the holding bolt, a stainless steel anchor for the propellant tube, an inconel spring, and a final boron nitride insulator. When completely assembled the spring was compressed, forcing the front insulator forward to form the gas-tight seals around the injection disk.

The propellant entered the arcjet through the side of the rear insulator. The propellant inlet tube was threaded on the end to match a tapped hole in the afore-mentioned anchor. The exterior surface of the boron nitride was flattened around the tube entrance. A support piece and flat washer were soldered to the propellant tube and a gas tight seal was made when the a graphite foll gasket was placed behind this and the insulator.

The cathode was connected to the power supply by a brass fitting that pressed onto the end of the cathode extended from the arcjet (not shown in figure) and the anode lead was connected to one of the clamping bolts used to hold the unit together. The arc gap was set by moving the cathode forward until it contacted the anode, measuring the entire unit, withdrawing the cathode the desired distance, and then tightening the fitting. The gap set to begin the tests described herein was $0.64 \mathrm{~mm}(0.025 \mathrm{in}$.).

The arcjet is shown mounted in the bell jar facility in figure 3 .

\section{PROCEDURE}

The procedures used for the diffusion pump facility and the bell jar facility were similar. Initially, in the diffusion pump facility, the cooling water for the thrust stand and the electronics were turned on and allowed to equilibrate. The thrust stand was calibrated before and after each run by use of weights suspended on a monofilament wire attached to a windlass. Following calibration a cold flow thrust measurement was taken of each of the hydrogen/ nitrogen gas mixtures used in this facility. The cold flow specific impulse 
was calculated and compared to other runs to insure no propellant leaks existed. Cold gas arcjet pressures were also recorded during this period.

The arcjet was started at the gas flow rates to be used in the run. In the diffusion pump facility, as the arcjet temperature increased the flow rates had to be adjusted manually to compensate for the changing chamber pressure so that the mass flow rate remained constant. The mass flow controllers in the bell jar facllity, however, were self adjusting and required no manual control as the arcjet chamber pressure increased.

In all tests performed the thruster was allowed to run for at least $20 \mathrm{~min}$ before voltage and/or thrust measurements were taken. This allowed the thruster body to attain thermal equilibrium and assured constant voltage readings. The voltage readings were taken at an initial current value of $10 \mathrm{~A}$. In the bell jar, after $1 \mathrm{~min}$, the current was increased to $12 \mathrm{~A}$ and, after another $30 \mathrm{sec}$ period elapsed, another voltage reading was taken. The current was then decreased by increments of 1 to $7 \mathrm{~A}$ with voltage readings taken at each current level after at least a $30 \mathrm{sec}$ period had elapsed. This $30 \mathrm{sec}$ period allowed the voltage reading to equilibrate. The current was then increased from 7 to $12 \mathrm{~A}$ with voltage readings taken as before. When these readings had been completed a new flow rate was selected and the procedure was repeated to obtain new volt-amp characteristics. In the diffusion pump facility the procedure was the same except that the thruster was allowed to remain at each current level for 3 to $5 \mathrm{~min}$ to allow the thruster to reattain thermal equilibrium so as to assure that accurate thrust measurements were obtained. For the thrust measurements, following each run the gas flow was shut off shortly after the arc was extinguished to check for a thermal shift in the zero of the thrust measurement.

In the diffusion pump facility molar hydrogen/nitrogen mixture ratios of 3:1 (simulated ammonia) and 2:1 (simulated hydrazine) were used. In the bell jar facility simulated ammonia and hydrazine mixtures were used as well as pure ammonia. Also, mixtures of 45 percent hydrogen/45 percent nitrogen/ 10 percent ammonia, 40 percent hydrogen $/ 40$ percent nitrogen/20 percent ammonia and 50 percent hydrogen/50 percent nitrogen were used in the bell jar faclitity. In addition, a 50 percent hydrogen/30 percent nitrogen/20 percent ammonia mi $x$ ture was used in the bell jar facility to simulate the gases exiting a hydrazine catalyst bed. (All percentages are based on molar quantities of the gas.) Comparisons were made of the arcjet volt-ampere characteristics using each of these gas mixtures.

\section{RESULTS AND DISCUSSION}

\section{Plume Behavior}

Figure 4 shows the arcjet plume in the bell jar at 7 A with a 2:1 hydrogen/ nitrogen mixture at a flow rate of $0.050 \mathrm{~g} / \mathrm{sec}$. With hydrogen $/ \mathrm{nitrogen} \mathrm{mix-}$ tures the visible plume was pink and diffuse. At its widest point the diameter of the luminous area of the plume was approximately 60 percent of the diameter of the arcjet body. Figure 5 shows the arcjet at a current of 12 A for the same hydrogen/nitrogen flow rate. At this higher current the plume was larger than the plume at $7 \mathrm{~A}$, with a luminous plume diameter approximately 85 percent of the arcjet body diameter. Also, it appears that the plume may actually have 
diffuse attachment to the arcjet body, rather than just in the nozzle, at $12 \mathrm{~A}$. This same behavior was observed for the 3:1 hydrogen/nitrogen gas mixtures.

In contrast, figure 6 shows the arc plume at $10 \mathrm{~A}$ with ammonia at $0.044 \mathrm{~g} / \mathrm{sec}$. The ammonia plume was more constricted than the hydrogen/ nitrogen plume, with a plume diameter approximately 35 percent of the diameter of the arcjet. The ammonia plume was green, and the plume itself appeared to be slightly off-center, possibly due to uneven attachment of the arc. The behavior was similar with 10 and 20 percent ammonia mixtures.

For the tests in the bell jar the arcjet plumes appeared to be less expanded than the plumes seen in the tests in the diffusion pump facility. This observation was similar to the one discussed in reference 17 . It therefore appears that ambient pressure as well as current level and propellant type affect the appearance of the plume.

\section{Volt-Ampere Characteristics}

The volt-ampere characteristics of the arcjet tested in the bell jar are given for various flow rates and propellant types in tables I-V. From the variations in the readout devices the uncertainty in the voltage measurements were estimated to be $\pm 1 \mathrm{~V}$. Similarly, the uncertainty in the current was estimated at $\pm 0.2 \mathrm{~A}$. The total uncertainty was approximately $\pm 2 \mathrm{~V}$.

Figure 7 and table I show the volt-amp characteristics with simulated hydrazine in a 2:1 hydrogen/nitrogen ratto. The curves in the figure 111 ustrate typical arcjet behavior seen throughout the tests on all the propellant mixtures examined. In all tests the voltage level was seen to decrease with increasing current levels. In the current range used in these tests, higher currents lead to hotter, and thus more electrically conductive, arc cores which are responsible for the voltage decrease (ref. 18). Increased current also led to increased arcjet body temperatures as evidenced by increased radiation from the thruster. This was due mainiy to increased heat input to the anode from several sources ( $r$ ef. 8 ). Of these, the energy related to the electron temperature, the anode fall, and the work function of the material are all directly proportional to current, while energy input due to radiation and convection increase to some extent with current (refs. 19 and 20 ). The gas flow rate also had an effect on the arc voltage; as the flow rate increased the arc voltage also increased. Increasing the flow rate increased the pressure, which increased the collison frequency of all species in the flow. This increased the rate at which energy is lost from the column and the recombination rate of charge carriers in the arc. Thus, a higher voltage gradient was required to sustain the arc at higher flow rates. Finally, it was observed that, in general, at low gas flow rates and low current levels the arc operation became somewhat erratic, with some voltage excursions observed. At high flow rates and high current levels similar voltage excursions were seen. These observations suggest a definite range of operation, dependent on design, with an arcjet.

Shown in figure 8 is a comparison of the $V$ - I characteristics of arcjet tests with $3: 1$ and 2:1 hydrogen/nitrogen mixtures to simulate ammonia and hydrazine, respectively. The volt-ampere characteristics for the 3:1 hydrogen/ nitrogen mixture are given in table II. The comparison shows that at similar mass flow rates the $3: 1$ mixture ran approximately 10 volts higher than the 2:1 
mixtures. This result has been previousiy noted (ref. 6) and is due to the fact that hydrogen is more effective at transferring energy from the arc. Thus, mixtures with higher percentages of hydrogen require larger voltage gradients to sustain the arc. Figure 9 shows the $V$-I characteristics with both pure ammonia (values given in table III) and a $3: 1$ hydrogen/nitrogen mixture. A comparison of the curves shows that the pure ammonia and the simulated anmonia mixture gave approximately the same voltages. While differences in plume characteristics noted earlier indicate some differences in plume species, the similar voltage characteristics indicate species and processes which may be similar. It should be noted that during some of the pure ammonia tests expulsion of molten material was observed. During this expulsion, which was also seen in a previous study (ref. 12), instantaneous voltage fluctuations were observed. These expulsions were probably the result of changes in the arc attachment point. During the test, however, over nine hr of operation on ammonia was accumulated with no apparent change in operation. This operating time exceeded the $2 \mathrm{hr}$ operating time obtained previously (ref. 12).

Tables IV to VI show the V-I characteristics of arcjet runs on mixtures of 40 percent hydrogen/40 percent nitrogen $/ 20$ percent ammonla, 45 percent hydrogen/45 percent nitrogen/10 percent ammonia, and 50 percent hydrogen/ 50 percent nitrogen, respectively. In these tests, as in the testing with hydrogen/nitrogen mixtures, various mass flow rates were run in the range anticipated for arcjet applications. As expected, increasing the mass flow rate had the effect of increasing the voltage values. For comparison between tests a single mass flow rate, $0.044 \mathrm{~g} / \mathrm{sec}$, was chosen and run for each mixture composition. The results are shown in figure 10. A maximum difference of approximately $4 \mathrm{~V}$ was seen between the 20 percent ammonia mixture and the 10 percent ammonia mixture. This difference was just outside the uncertainty ranges of the measurements. It should be noted that the mass flow rate for the mixture with 10 percent ammonia was inadvertently set to a level about 2 percent below the other two tests and that this would lead to slightly lower voltage measurements. The 50 percent hydrogen/50 percent nitrogen mixture had a lower voltage than the 10 percent ammonia mixture, with a maximum voltage difference of about $5 \mathrm{~V}$. From the trend indicated by the figure it appears that the addition of ammonia to an equimolar stream of hydrogen and nitrogen increased the voltage. This result was consistent with the results discussed above. The ammonia dissociates into nitrogen and hydrogen upon heating, producing higher hydrogen/nitrogen ratios in the gas stream. The increased hydrogen content increased the voltage, as discussed previously. Therefore, the results of the hydrogen/nitrogen/ammonia mixtures indicated that the small amounts of ammonia present in the gas stream can have an effect on the arcjet operating characteristics.

Figure 11 compares the $V$ - I characteristics for simulated hydrazine mixtures. From the figure it can be seen that the voltages of the 50 percent hydrogen/30 percent nitrogen/20 percent ammonia mixture (given in table VII) were approximately $7 \mathrm{~V}$ higher than those of the $2: 1$ hydrogen/nitrogen mixtures at the same flow rate. Because the simulated ammonia and pure ammonia mixtures produced approximately the same V-I characteristics, it was expected that the voltages of the hydrazine cases would also be the same. However, although the voltage differences between the simulated hydrazine cases were statistically small, they were significant. Because the exact nature of the kinetics and thermal processes of the arcjet are not known, further study will be required to determine the reasons behind this voltage difference. 
Finally, figures 12 and 13 show the arcjet $V$-I characteristics from tests both in the bell jar faclilty and in the diffusion pump facility (tables VIII and $I X)$. Figure 12 compares tests run with $3: 1$ hydrogen/nitrogen mixtures while figure 13 compares tests run with $2: 1$ mixture ratios. For both mixtures the voltages differ by 3 to $5 \mathrm{~V}$ with the readings taken in the lower pressure environment being the higher of the two. This difference is only sightly outside the afore-mentioned range of uncertainty, and was originally thought to have been due to a slight shift in the position of the anode attachment zone.

An additional test was performed in the diffusion pump facility to determine the cause of the voltage difference. In this test the facility was run using only the roughing pump and blower, producing a ambient pressure of approximately 0.23 torr at normal hydrogen/nitrogen flow rates. The comparison between the $V$-I characteristics in this test and those in the test at low ambient pressure (10-4 torr) is shown in figure 14. As can be seen by the figure there was essentially no difference in voltage between the two tests. Thus, the small difference in voltages discussed previously was probably due to facility effects, such as a difference in the voltage drop at the connecting point of the current leads, and not due to a change in anode attachment. The voltage difference seen in the comparison between facilities would not, however, be expected to have a significant impact on the performance or lifetime of the arcjet.

\section{Performance}

Typical performance data for the thruster used in these tests are shown in figure 15. In the figure specific impulse (Isp) is plotted versus power-tomass flow rate for each of the five mass flow rates, two simulating the decomposition products of hydrazine and three simulating ammonia. In each test the mass flow rate was held constant and the power varied by adjusting the current between 7 and $12 \mathrm{~A}$. With the exception of the lowest flow rate, all the curves display the same general trends with the specific impulse lowest at the lowest power-to-mass flow rate (lowest current level). At each point the specific impulse was greater than $400 \mathrm{sec}$ and there was a variation of 40 to $80 \mathrm{sec}$ Isp between the highest and lowest current level at each mass flow rate. As expected, the ammonia mixtures gave specific impulse levels approximately $10 \mathrm{sec}$ higher than the hydrazine mixtures at a given power-to-mass flow rate. For both propellant mixtures the higher mass flow rates gave higher specific impulse levels at constant power-to-mass flow ratio. The anamolous curve was obtained with the lowest mass flow rate, and the arcjet showed, at times, a considerable amount of instability at this level. Further investigation of the stable operating range of the arcjet is now in progress.

A comparison of the performance of the arcjet at high and low ambient pressures is shown in figure 16. From the figure it can be seen that the ratio of high background pressure specific impulse to low ambient pressure specific impulse was between 0.94 and 0.95 for the range of power-to-mass flow rate ratios. A pressure-area correction, similar to that performed in reference 21 , did not account for this difference in specific impulse. Although the performance differences between the two cases were small, the effect of ambient pressure on arcjet operation must be investigated further before conclusions can be drawn. 
In this study tests were performed to compare the volt-ampere characteristics of the arcjet run with various mixtures of hydrogen, nitrogen, and ammonia. Some general results were evident for all propellant mixtures examined. Over the current range tested, voltage decreased with increasing current. For the range of propellant mass flow rates used, increases in the mass flow rate led to increases in the voltage. These results have been noted previousiy. In addition, a definite range of stable operation was indicated as erratic operation was observed both at low current levels with low gas flow rates and high current levels with high gas flow rates.

From the results of the tests designed to compare arcjet operation between high and relatively low ambient pressure vacuum facilities it was found that the operating characteristics were about the same. The voltages measured in the diffusion pump facility were 3 to $5 \mathrm{~V}$ higher than those measured in the bell jar facility, at a given mass flow rate and current. This difference, which was only slightly larger than the experimental uncertainty, implies that the arcjet was operating in the same mode in each case. An additional test performed in the diffusion pump facility at both high and low ambient pressures showed that there was no significant difference in V-I characteristics with a change in ambient pressure. Therefore, the differences noted were probably due to differences in the voltage drop across the current connection points rather than arcjet operational differences in the two facllities. The fact that the differences were small and not pressure related indicates that testing in small bell jar factlities, done because of the cost and lack of avallability of larger facilities, is probably valid.

The bell jar tests in which the arcjet was operated at constant mass flow but with hydrogen/nitrogen/ammonia mixtures composed of differing percentages of ammonia ( 0 to 20 percent) did show some difference in operating characteristics. This indicates that increasing the fraction of ammonia in the propellant stream does affect arcjet operation by increasing the hydrogen content of the gas, thus increasing the voltage. When simulated hydrazine mixtures were compared an unexpected voltage difference was observed. The reason for this difference is presently under investigation.

Finally, bell jar tests comparing arcjet characteristics with pure ammonia and simulated ammonia (hydrogen/nitrogen mixtures in a $3: 1$ ratio) showed that there was no significant difference in the $V$-I characteristics. During the ammonia test there was some expulsion of molten material observed, but because the arcjet was run for over $9 \mathrm{hr}$ with ammonia in these tests it appears that extended operation of the arcjet is feasible with pure ammonia or ammonia mixtures at low power levels.

\section{REFERENCES}

1. Smith, W.W. and Knowles, S.C., "Analysis of Electric Propulsion Concepts for Near-Term Applications," 1985 JANNAF P.ropulsion Meeting, Vol. 1 , K.L. Strange, ed., CPIA-PUBL-425-VOL-1, Chemical Propulsion Agency, Laure 1, MD, 1985, PD. 457-467. 
2. Knowles, S.C., Smith, W.W., Chun, S.I., and Feconda, R.T., "Low Power Hydrazine Arcjets A System Description for Near-Term Application, "1986 JANMAF Propulsion Meeting, Vol. 1, K.L. Strange and D.S. Eggleston, eds., CPIA-PUBL-455-VOL-1, Chemical Propulsion Agency, Laure1, MD, 1985, pp. 399-403.

3. McKevitt, F.X., "Design and Development Approach for the Augmented Catalytic Thruster (ACT)," AIAA Paper 83-1255, June 1983.

4. Curran, F.M. and Whaten, M.V., "In-Situ Analysis of Hydrazine Decomposition Products," AIAA Paper 87-2122, June 1987. (A1so, NASA TM-89916).

5. Nakanishi, S., "Experimental Performance of a 1-Kilowatt Arcjet Thruster," AIAA Paper 85-2033, Oct. 1985.

6. Curran, F.M. and Nakanishi, S., "Low Power dc Arcjet Operation with Hydrogen/Nitrogen Propellant Mixtures," AIAA Paper 86-1505, June 1986.

7. Gruber, R.P., "Power Electronics for a 1 Kllowatt Arcjet Thruster," AIAA Paper 86-1507, June 1986. (Also, NASA TM-87340).

8. Curran, F.M., "An Experimental Study of Energy Loss Mechanisms and Efficiency Considerations in the Low Power dc Arcjet," AIAA Paper 85-2017, Oct. 1985. (Also, NASA TM-87123).

9. Haag, T.W. and Curran, F.M., "Arcjet Starting Reliability: A Multistart Test on Hydrogen/Nitrogen Mixtures," AIAA Paper 87-1061, May 1987. (Also, NASA TM-89867).

10. Curran, F.M. and Haag, T.W., "Arcjet Component Conditions Through a Multistart Test," AIAA Paper 87-1060, May 1987. (A7so, NASA TM-89857).

11. Knowles, S.C., Smith, W.W., Curran, F.M., and Haag, T.W., "Performance Characterization of a Low Power Hydrazine Arcjet," AIAA Paper 87-1057, May 1987.

12. Meltzer, J., Chen, C.J., Greco, R., McKenna, Q., Mitcheltree, G., Price, $R$., and Stoner, W., "Properties of Plasmas as They Pertain to Thermal Arc-Jets," Wright Patterson Atr Force Base, Aeronautical Systems Division, ASD-TDR-451, Aug. 1962.

13. Greco, R.V. and Stoner, W.A., "Research and Development of a 1-kw Plasmajet Thruster," AIAA Journal, Vol. 1, No. 2, Feb. 1963, pp. 320-324.

14. Simon, M.A., Knowles, S.C., Curran, F.M., and Hardy, T.L., "Low Power Arcjet Life Issues," AIAA Paper 87-1059, May 1987.

15. Geideman, W.A. Jr. and Muller, K., "Development Status of Low-Power Arc-Jet Engtnes," Journal of Spacecraft and Rockets, Vol. 2, No. 5, Sept. -Oct. 1965, pp. 718-723.

16. McCaughey, 0.J., Geideman, W.A. Jr., and Muller, K., "Research and Advanced Development of a 2 kw Arc-Jet Thruster," NASA CR-54035, 1963. 
17. Oucat1, A.C., Humpal, H., Meltzer, J., Muehlberger, E., Todd, J.P., and Waltzer, H., "l-kw Arcjet-Engine System-Performance Test," Journal of Spacecraft and Rockets, Vol. 1, No. 3, May-June 1964, pp. 327-332.

18. Finkelnburg, W. and Maecker, H., "Electric Arcs and Thermal Plasma," Union Carbide Corp., ARL-62-302, Jan. 1962. (Ava11. NTIS, AD-850250).

19. Chen, M., Conners, J.F., and John R.R., "Theoretical and Experimental Research on Thermal Arc Jets," Air Force Materials Laboratory Report ASD-TDR-62-616, Aug. 1962. (Ava11. NTIS, AD-408774).

20. John R.R., et al, "Theoretical and Experimental Investigation of Arc Plasma-Generation Technology, "Wright Patterson Air Force Base, ASD-TDR-62-729, Sept. 1963.

21. Penko, P.F., Manzella, D.H., Dewitt, K.J., and Keith, T.G., "Effect of Ambient Pressure on the Performance of a Resistojet," AIAA Paper 87-991, May 1987.

TABLE I. - VOLT-AMPERE CHARACTERISTICS WITH 2:1 HYDROGEN/NITROGEN MIXTURES BELL JAR FACILITY TESTS

\begin{tabular}{|c|c|c|}
\hline $\begin{array}{c}\text { Flow rate, } \\
\text { g/sec }\end{array}$ & $\begin{array}{c}\text { Current, } \\
\text { A }\end{array}$ & $\begin{array}{c}\text { Voltage, } \\
\text { V }\end{array}$ \\
\hline 0.039 & 7 & 115.3 \\
& 8 & 110.9 \\
& 9 & 107.4 \\
& 10 & 104.7 \\
& 11 & 102.3 \\
& 12 & 100.3 \\
\hline 0.044 & 7 & 119.1 \\
& 8 & 114.5 \\
& 9 & 111.1 \\
& 10 & 108.2 \\
& 11 & 105.9 \\
& 12 & 103.9 \\
\hline 0.052 & 7 & 124.6 \\
& 8 & 119.9 \\
& 9 & 116.1 \\
& 10 & 113.1 \\
& 11 & 110.5 \\
& 12 & 108.4 \\
\hline 0.048 & 8 & 115.7 \\
& 9 & 112.2 \\
& 10 & 109.5 \\
& 11 & 107.2 \\
& 12 & 105.1 \\
\hline
\end{tabular}

TABLE II. - VOLT-AMPERE CHARACTERISTICS WITH 3:1 HYDROGEN/NITROGEN MIXTURES BELL JAR FACILITY TESTS

\begin{tabular}{|c|c|c|}
\hline $\begin{array}{c}\text { Flow rate, } \\
\text { g/sec }\end{array}$ & $\begin{array}{c}\text { Current, } \\
A\end{array}$ & $\begin{array}{c}\text { Voltage, } \\
\text { V }\end{array}$ \\
\hline 0.034 & 7 & 117.2 \\
& 8 & 113.3 \\
& 9 & 109.8 \\
& 10 & 107.0 \\
& 11 & 104.5 \\
& 12 & 102.5 \\
\hline 0.039 & 7 & 125.5 \\
& 8 & 120.9 \\
& 9 & 117.0 \\
& 10 & 113.9 \\
& 11 & 111.3 \\
& 12 & 109.3 \\
\hline \multirow{2}{*}{0.047} & 7 & 129.4 \\
& 8 & 124.6 \\
& 9 & 120.7 \\
& 10 & 117.7 \\
& 11 & 115.1 \\
& 12 & 112.5 \\
\hline
\end{tabular}


TABLE III. - VOLT-AMPERE CHARACTERISTICS WITH AMMONIA. BELL JAR FACILITY TESTS

\begin{tabular}{|c|c|c|}
\hline $\begin{array}{c}\text { Flow rate, } \\
\text { g/sec }\end{array}$ & $\begin{array}{c}\text { Current, } \\
\text { A }\end{array}$ & $\begin{array}{c}\text { Voltage, } \\
\text { V }\end{array}$ \\
\hline 0.033 & 7 & 118.4 \\
& 8 & 114.2 \\
& 9 & 110.9 \\
& 10 & 107.8 \\
& 11 & 105.6 \\
& 12 & 103.4 \\
\hline 0.037 & 7 & 121.3 \\
& 8 & 117.8 \\
& 9 & 114.7 \\
& 10 & 111.8 \\
& 17 & 109.6 \\
& 12 & 107.5 \\
\hline 0.041 & 7 & 125.3 \\
& 8 & 121.1 \\
& 9 & 118.0 \\
& 10 & 115.6 \\
& 11 & 113.2 \\
& 12 & 111.1 \\
\hline 0.044 & 7 & 128.1 \\
& 8 & 124.1 \\
& 9 & 120.7 \\
& 10 & 117.8 \\
& 11 & 114.8 \\
\hline
\end{tabular}


TABLE IV. - VOLT-AMPERE CHARACTERISTICS WITH A 40 PERCENT HYDROGEN/40 PERCENT NITROGEN/

20 PERCENT AMMONIA MIXTURE

BELL JAR FACILITY TESTS

\begin{tabular}{|c|c|c|}
\hline $\begin{array}{c}\text { Flow rate, } \\
\text { g/sec }\end{array}$ & $\begin{array}{c}\text { Current, } \\
\text { A }\end{array}$ & $\begin{array}{c}\text { Voltage, } \\
\mathrm{V}\end{array}$ \\
\hline 0.044 & 7 & 117.0 \\
& 8 & 112.7 \\
& 9 & 109.4 \\
& 10 & 107.0 \\
& 11 & 105.1 \\
& 12 & 103.3 \\
\hline 0.049 & 7 & 122.0 \\
& 8 & 117.3 \\
& 9 & 113.5 \\
& 10 & 111.1 \\
& 11 & 108.9 \\
& 12 & 107.2 \\
\hline 0.058 & 7 & 129.0 \\
& 8 & 125.0 \\
& 9 & 121.8 \\
& 10 & 118.9 \\
& 11 & 114.8 \\
\hline
\end{tabular}


TABLE V. - VOLT-AMPERE CHARACTERISTICS WITH A

45 PERCENT HYDROGEN/45 PERCENT NITROGEN/

10 PERCENT AMMONIA MIXTURE

BELL JAR FACILITY TESTS

\begin{tabular}{|c|c|c|}
\hline $\begin{array}{c}\text { Flow rate, } \\
\text { g/sec }\end{array}$ & $\begin{array}{c}\text { Current, } \\
A\end{array}$ & $\begin{array}{c}\text { Voltage, } \\
V\end{array}$ \\
\hline 0.038 & 7 & 109.6 \\
& 8 & 105.6 \\
& 9 & 102.6 \\
& 10 & 100.4 \\
& 11 & 98.3 \\
& 12 & 96.7 \\
\hline 0.043 & 7 & 115.4 \\
& 8 & 109.3 \\
& 9 & 106.1 \\
& 10 & 103.8 \\
& 11 & 101.9 \\
& 12 & 100.4 \\
\hline 0.051 & 7 & 118.6 \\
& 8 & 114.4 \\
& 9 & 111.0 \\
& 10 & 108.2 \\
& 11 & 106.5 \\
& 12 & 104.9 \\
\hline
\end{tabular}

TABLE VI. - VOLT-AMPERE CHARACTERISTICS WITH A 50 PERCENT HYDROGEN/50 PERCENT NITROGEN MIXTURE BELL JAR FACILITY TESTS

\begin{tabular}{|c|c|c|}
\hline $\begin{array}{c}\text { Flow rate, } \\
\text { g/sec }\end{array}$ & $\begin{array}{c}\text { Current, } \\
\text { A }\end{array}$ & $\begin{array}{c}\text { Voltage, } \\
\text { V }\end{array}$ \\
\hline 0.044 & 7 & ---- \\
& 8 & 104.2 \\
& 9 & 101.6 \\
& 10 & 99.0 \\
& 11 & 97.0 \\
& 12 & 95.4 \\
\hline
\end{tabular}


TABLE VII. - VOLT-AMPERE CHARACTERISTICS WITH A

50 PERCENT HYDROGEN/30 PERCENT NITROGEN/

20 PERCENT AMMONIA MIXTURE

BELL JAR FACILITY TESTS

\begin{tabular}{|c|c|c|}
\hline $\begin{array}{c}\text { Flow rate, } \\
\text { g/sec }\end{array}$ & $\begin{array}{c}\text { Current, } \\
\text { A }\end{array}$ & $\begin{array}{c}\text { Voltage, } \\
\text { V }\end{array}$ \\
\hline 0.044 & 7 & 124.7 \\
& 8 & 120.3 \\
& 9 & 116.9 \\
& 10 & 114.1 \\
& 11 & 111.8 \\
& 12 & - \\
\hline
\end{tabular}

TABLE VIII. - VOLT-AMPERE CHARACTERISTICS WITH 3:1 HYOROGEN/NITROGEN MIXTURES DIFFUSION PUMP FACILITY TESTS

\begin{tabular}{|c|c|c|}
\hline $\begin{array}{c}\text { Flow rate, } \\
\text { g/sec }\end{array}$ & $\begin{array}{c}\text { Current, } \\
\text { A }\end{array}$ & $\begin{array}{c}\text { Voltage, } \\
\text { V }\end{array}$ \\
\hline 0.023 & 9 & 101.0 \\
& 10 & 97.5 \\
& 11 & 95.0 \\
& 12 & 94.0 \\
\hline 0.028 & 9 & 107.0 \\
& 10 & 104.0 \\
& 11 & 102.0 \\
& 12 & 100.0 \\
\hline 0.034 & 7 & 121.0 \\
& 8 & 116.0 \\
& 9 & 114.0 \\
& 10 & 111.0 \\
& 11 & 109.0 \\
& 12 & 107.0 \\
\hline
\end{tabular}

TABLE IX. - VOLT-AMPERE CHARACTERISTICS WITH 2:1 HYDROGEN/NITROGEN MIXTURES DIFFUSION PUMP FACILITY TESTS

\begin{tabular}{|c|c|c|}
\hline $\begin{array}{c}\text { Flow rate, } \\
\text { g/sec }\end{array}$ & $\begin{array}{c}\text { Current, } \\
\text { A }\end{array}$ & $\begin{array}{c}\text { Voltage, } \\
\text { V }\end{array}$ \\
\hline 0.032 & 7 & -105.0 \\
& 8 & 105.0 \\
& 8.7 & 104.0 \\
& 10 & 100.0 \\
& 11 & 98.0 \\
& 12 & 96.0 \\
& 7 & -118.0 \\
& 8 & 114.0 \\
& 9 & 112.5 \\
& 10 & 110.0 \\
& 11 & 109.0 \\
\hline
\end{tabular}


ORICNAL PAGE IS

OF POOR QUALTY

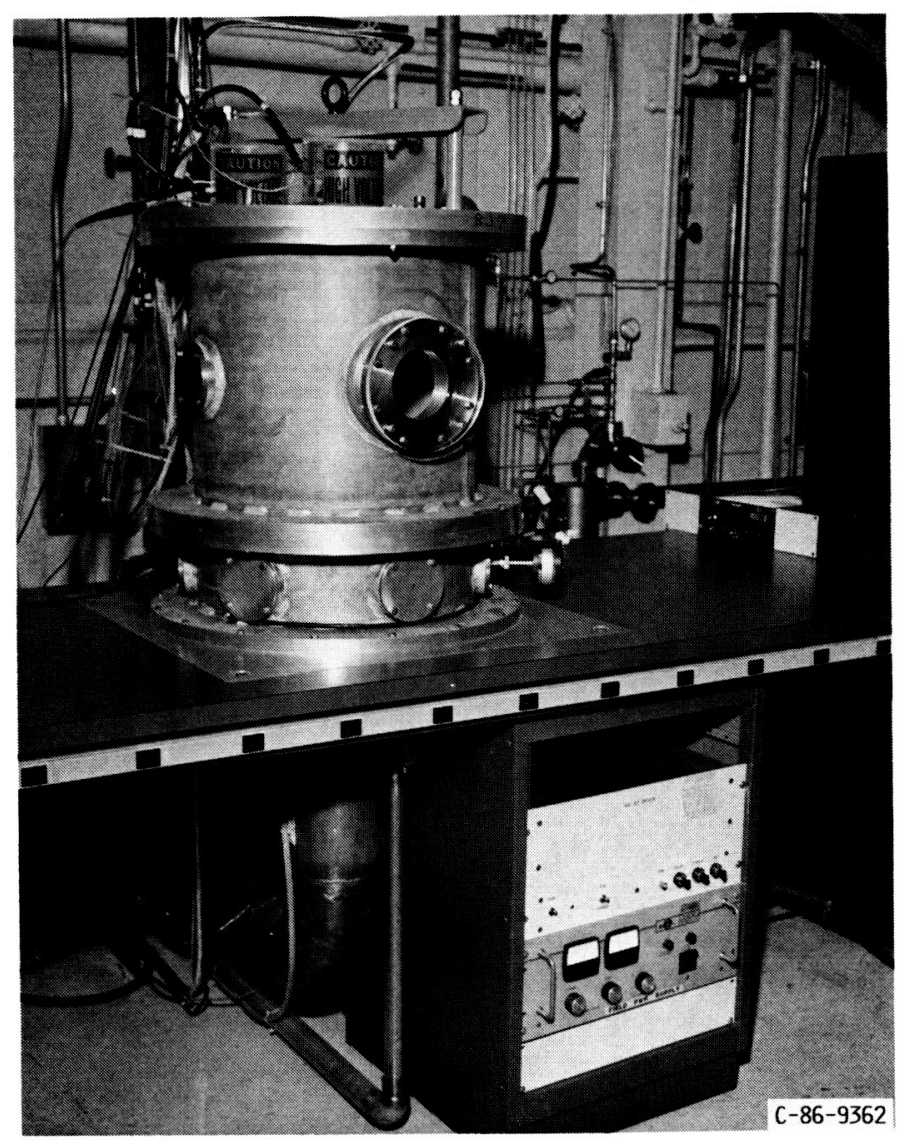

FIgURE 1. - BELL JAR FACILITY.

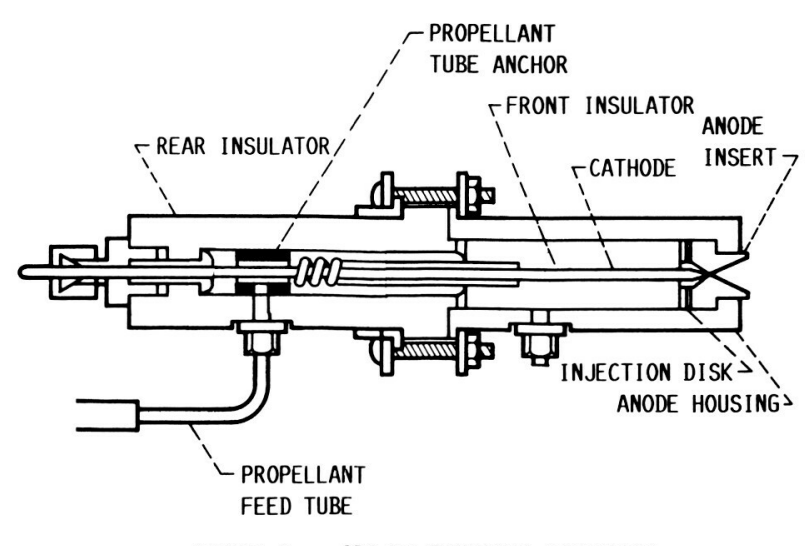

FIgURE 2. - ARCJET THRUSTER SCHEMATIC. 
ORIGNAL PAGE IS
OF POOF MALITY

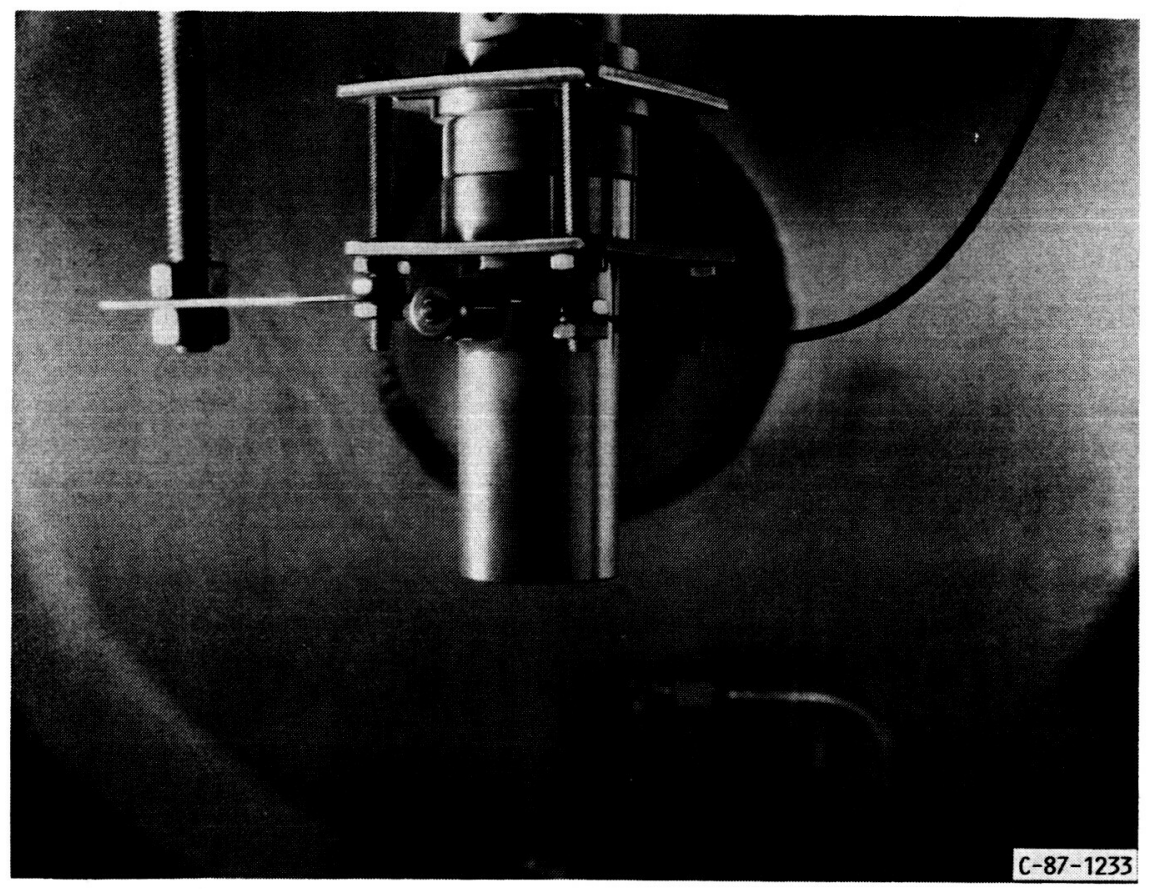

FIGURE 3. - ARCJET MOUNTED IN BELL JAR FACILITY. 


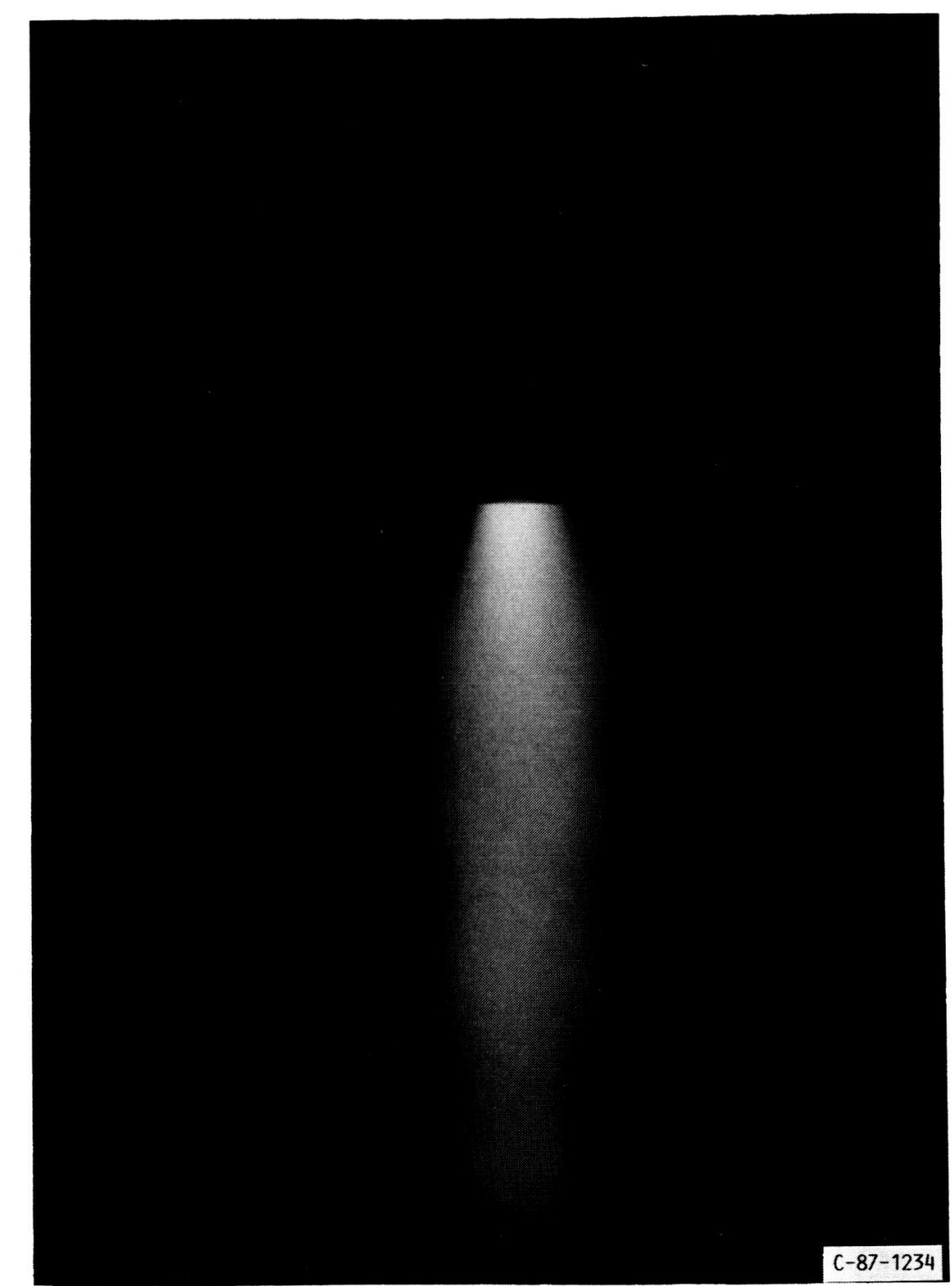

FIGURE 4. - ARCJET OPERATING IN BELL JAR AT 7 AMP, $0.050 \mathrm{~g} / \mathrm{SEC}, 2: 1 \mathrm{H} / 2 \mathrm{~N}_{2} \mathrm{MIX}-$ TURE. 


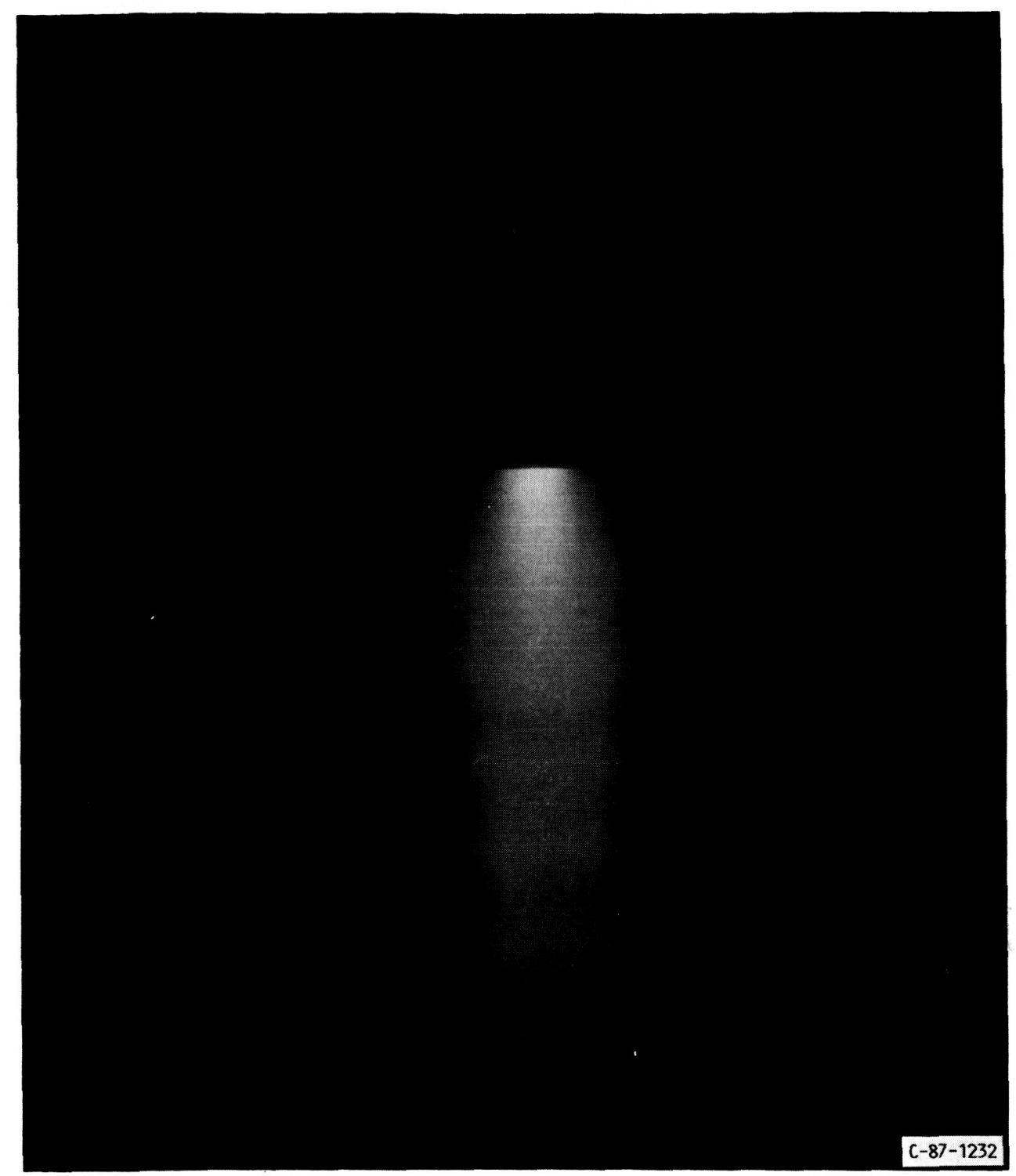

FIGURE 5. - ARC.JET OPERATING IN BELL JAR AT 12 AMP, $0.050 \mathrm{~g} / \mathrm{SEC}, 2: 1 \mathrm{H}_{2} / \mathrm{N}_{2}$ MIXTURE. 
OROINAL PAGE IS

OF POOR QUALTY

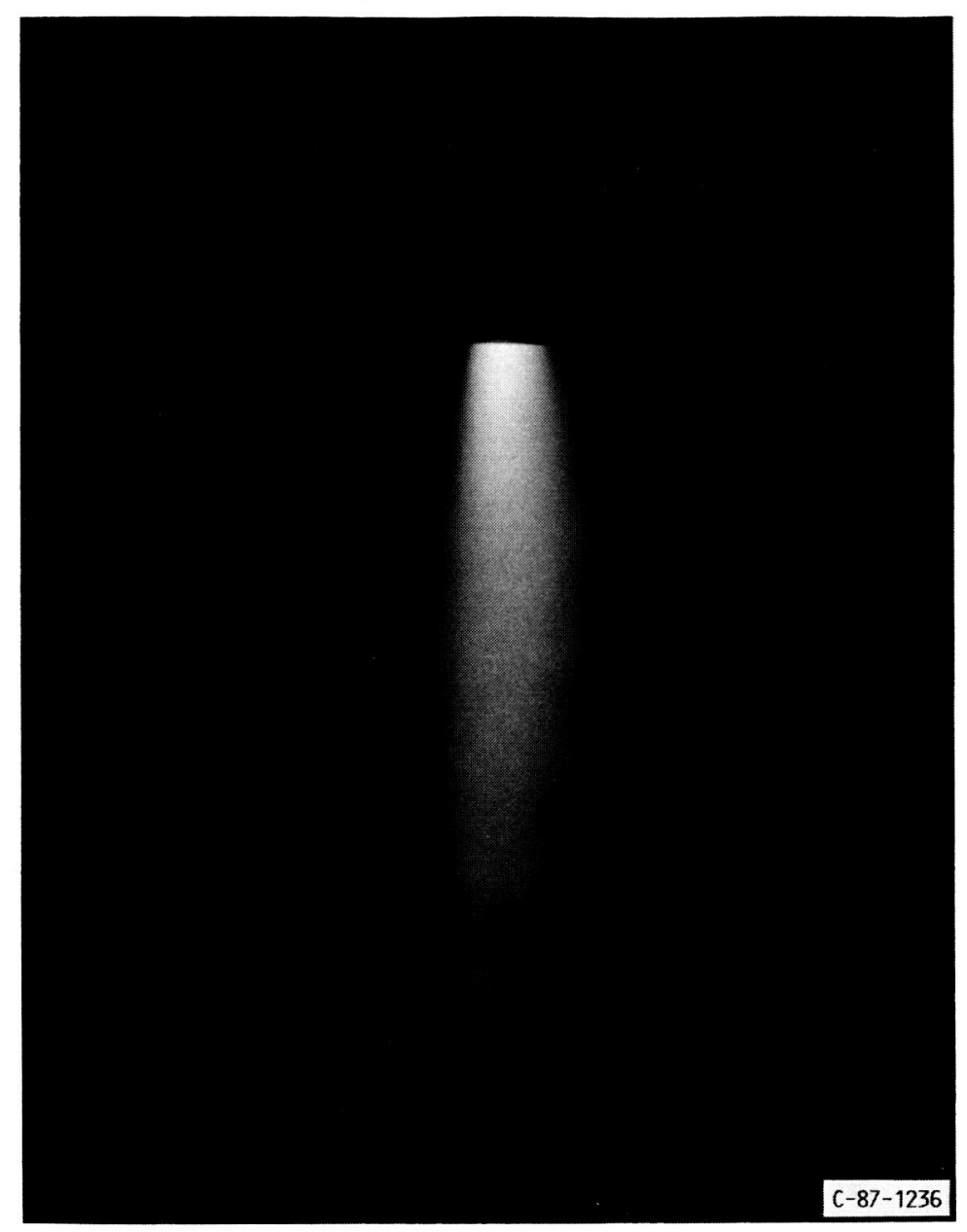

FIGURE 6. - ARCJET OPERATING IN BELL JAR AT $10 \mathrm{AMP}, 0.044 \mathrm{~g} / \mathrm{seC}$, AMMONIA. 


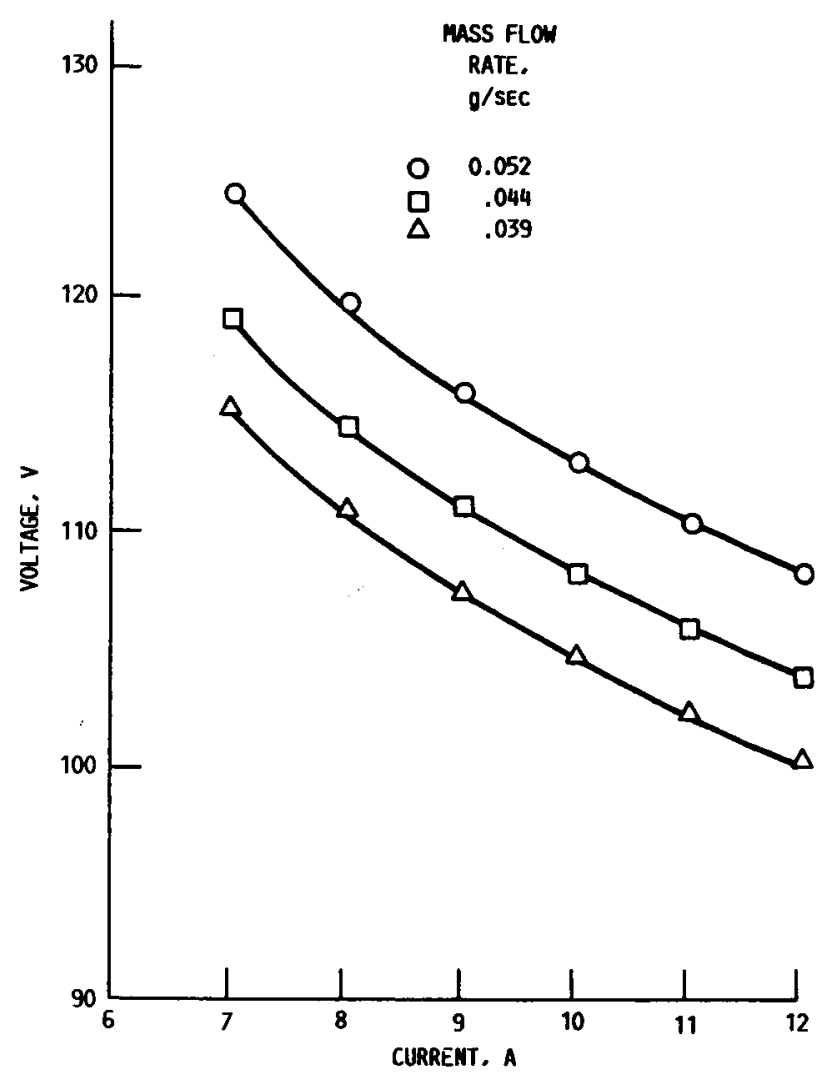

FIGURE 7. - VOLTAGE-CURREMT CHARACTERISTICS HITH 2:1 HYDROGEM/NITROGEN PROPELLANT MIXTURE (SIMULATED HYDRAZINE). BELL JAR FACILITY.

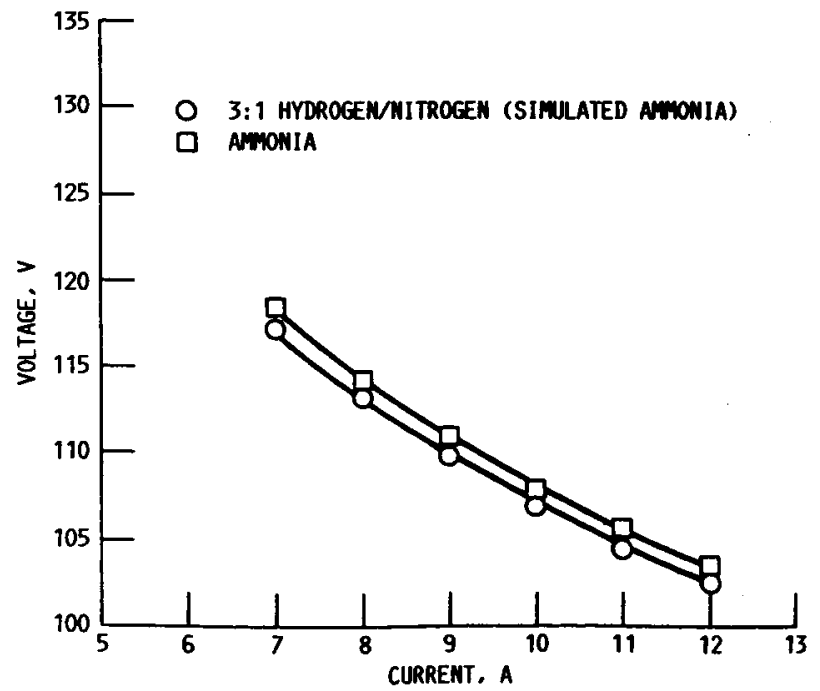

FIGURE 9. - COMPARISON OF THE VOLT-AMPERE CHARACTERISTICS FOR AMHONIA AMD 3:1 HYDROGEM/NITROGEN MIXTURES. BELL JAR FACILITY.

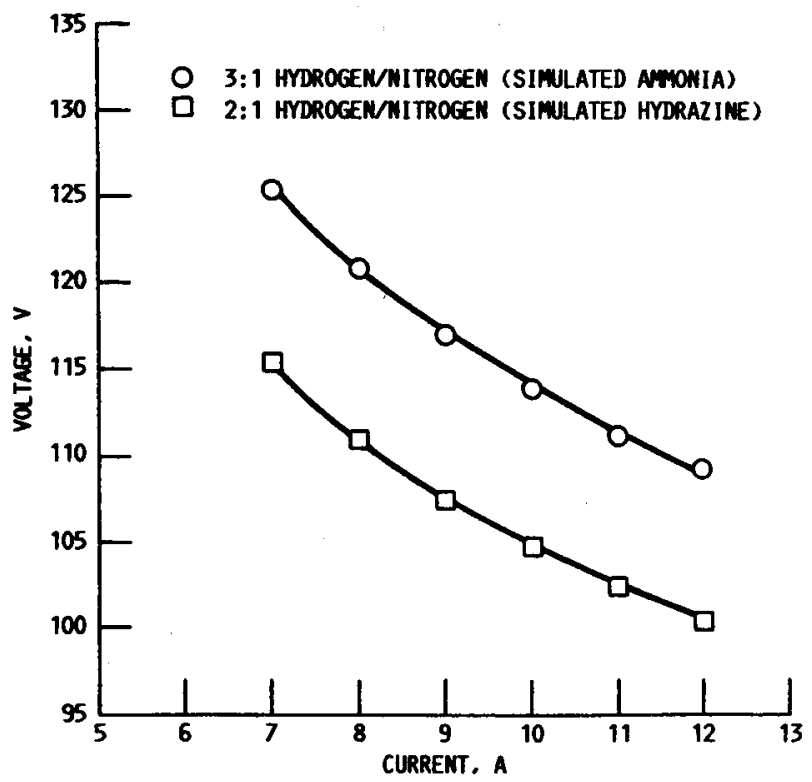

FIGURE 8. - COMPARISON OF THE VOLT-AMPERE CHARACTERISTICS FOR HYDROGEN/NITROGEN MIXTURES. BELL JAR FACILITY.

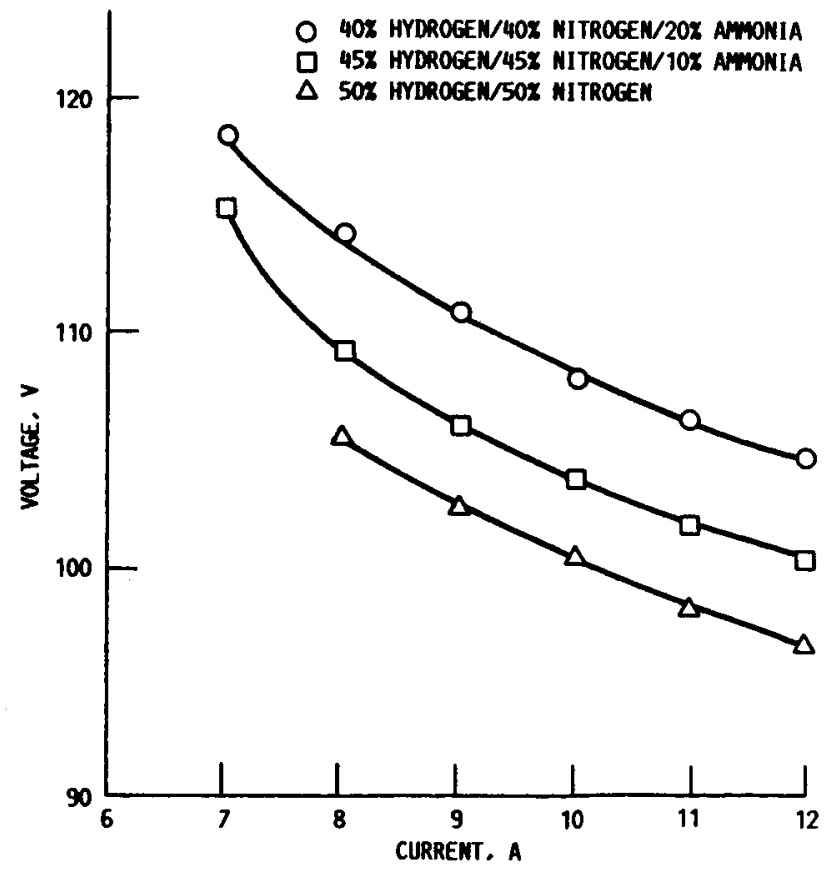

FIGURE 10. - COMPARISON OF THE VOLT-AMP CHARACTERISTICS HITH VARYING MIXTURES OF HYDROGEN, MITROGEN, AND AMONIA. MASS FLOW RATE $=0.044 \mathrm{~g} / \mathrm{sEC}$. BELL JAR FACILITY. 


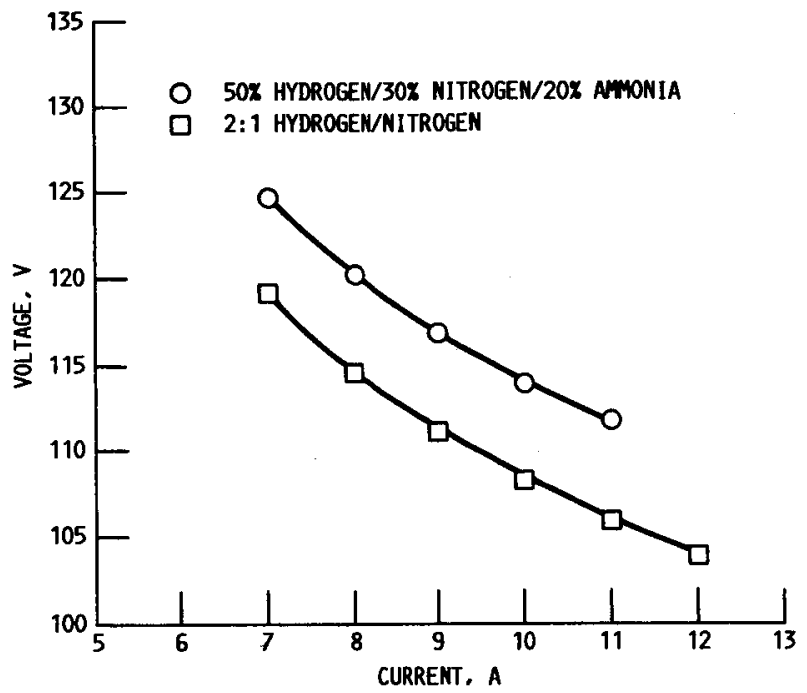

FIGURE 11. - COMPARISON OF VOLT-AMPERE CHARACTERISTICS FOR SIMULATED HYDRAZINE MIXTURES. MASS FLOW RATE $=0.044$ $g /$ SEC, BELL JAR FACILITY.

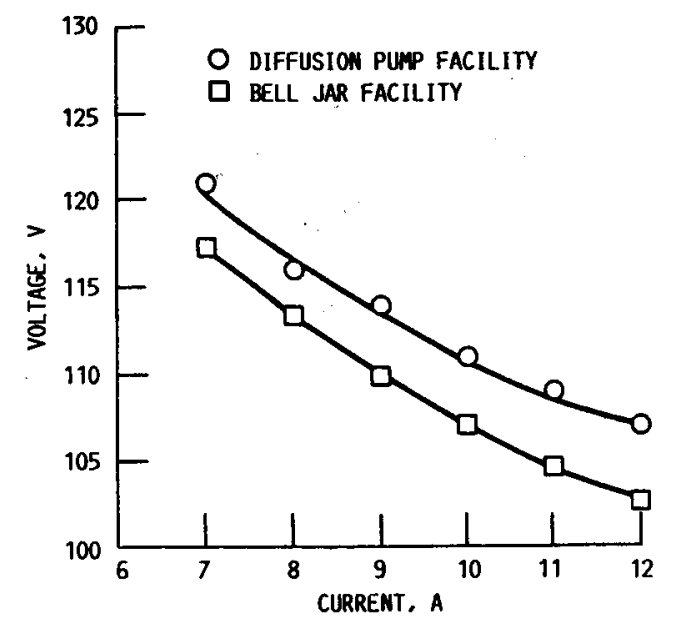

FIGURE 12. - VOLTAGE-CURRENT CHARACTERISTICS WITH A 3:1 HYDROGEN/NITROGEN MIXTURE (SIMULATED AMNONIA). MASS FLOW RATE $=0.034$ g/SEC. FACILITY COMPARISON.

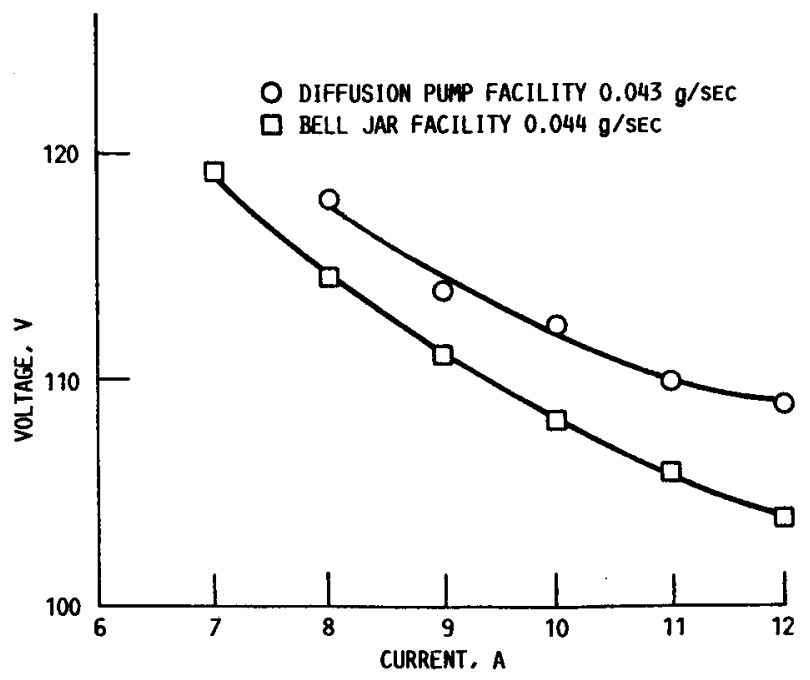

FIGURE 13. - VOLIAGE-CURRENT CHARACTERISTICS HITH A 2:1 HYDROGEN/NITROGEN PROPELLANT MIXTURE (SIMULATED HYDRAZINE). FACILITY COMPARISON. 


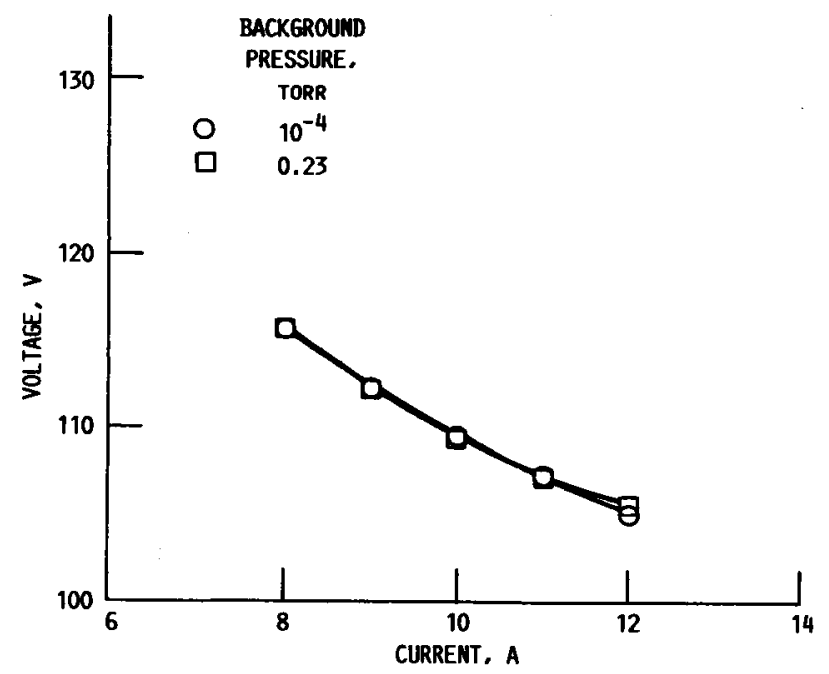

FIGURE 14. - COMPARISON OF VOLT-AMP CHARACTERISTICS OF THE ARCJET RUN IN THE DIFFUSIOW PUAP FACILITY AT DIFFERENT AMBIENT PRESSURES. MASS FLOW RATE $=0.048 \mathrm{~g} / \mathrm{sEC}$, SIMULATED HYDRAZIME MIXTURE.

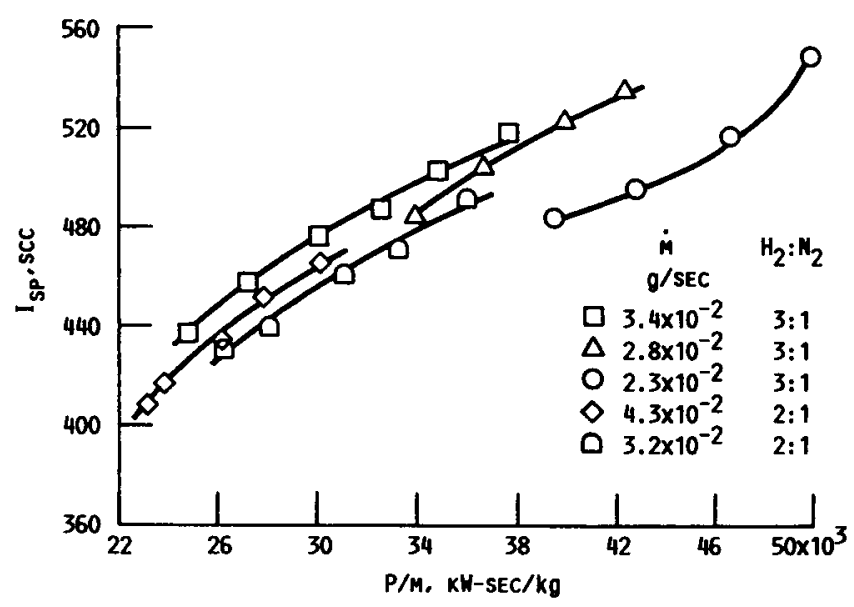

FIGURE 15. - ARCJET SPECIFIC IMPULSE VERSUS POWER-TO-MASS FLOW RATE FOR VARIOUS FLOW RATES.

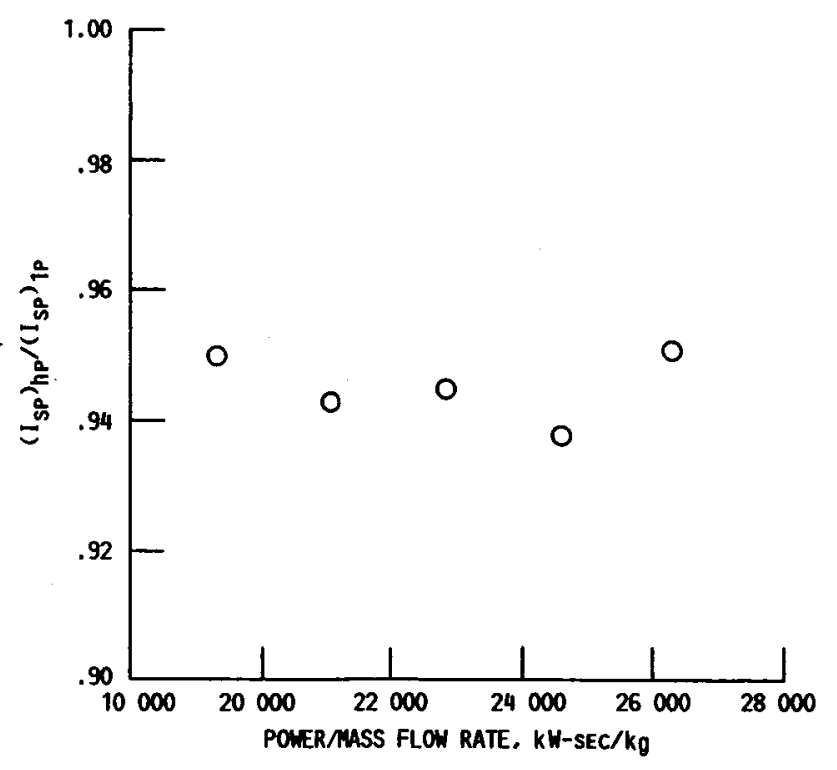

FIGURE 16. - RATIO OF HIGH AMBIENT PRESSURE SPECIFIC IRPULSE $\left(\left(I_{S P}\right) h_{P}\right)$ TO LOW AMBIENT PRESSURE SPECIFIC INPULSE $\left(\left(I_{S P}\right)_{1 P}\right)$ VERSUS POWER-TO-MASS FLOW RATE.

MASS FLOW RATE $=0.048 \mathrm{~g} / \mathrm{sEC}$. 


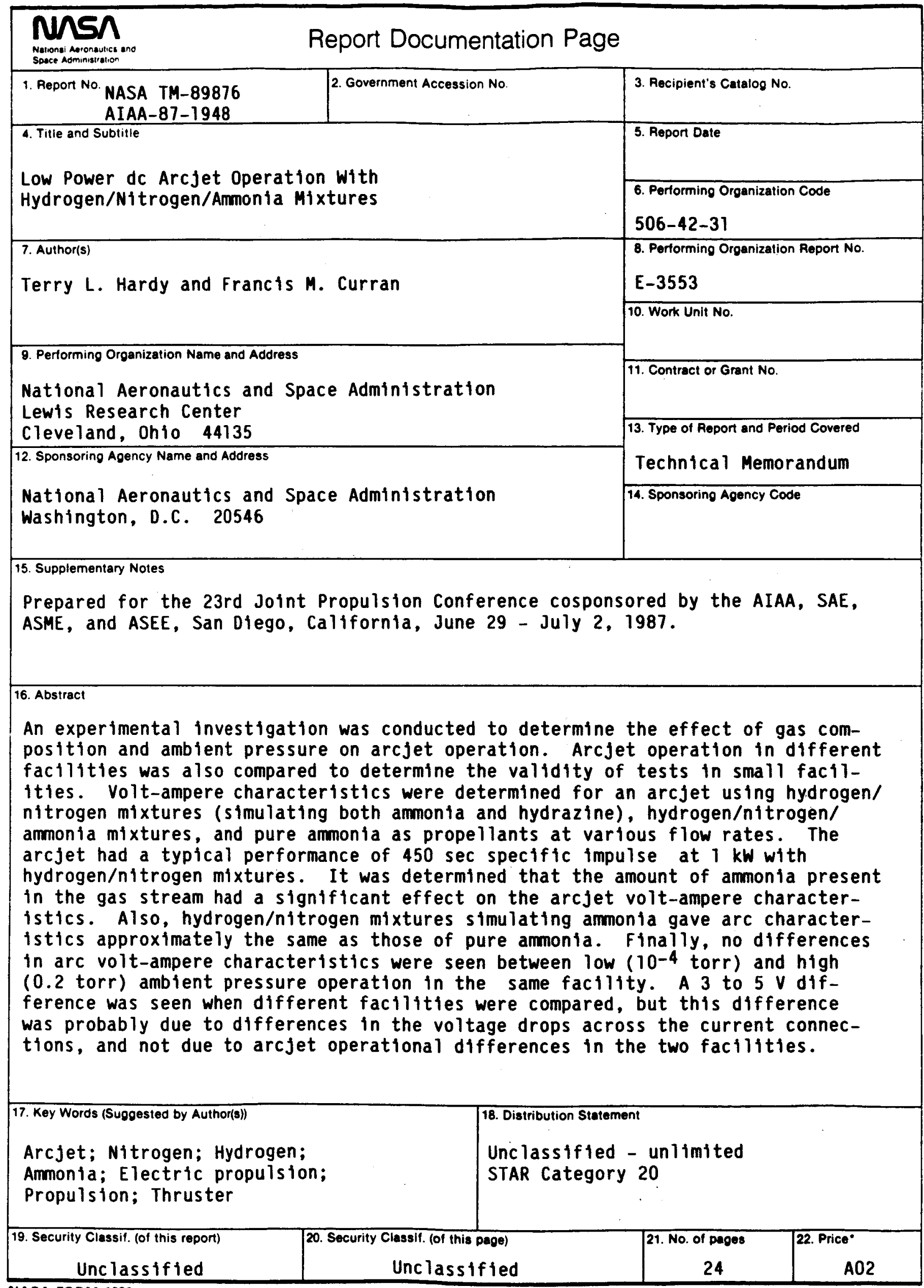

NASA FORM 1626 oct 86 "For sale by the National Technical Information Service, Springfield, Virginia 22161 